\title{
APLIKASI PROSES BIOFILTRASI DAN ULTRA FILTRASI UNTUK PENGOLAHAN AIR MINUM
}

\author{
Oleh : \\ Nusa Idaman Said \\ Pusat Teknologi Lingkungan, Badan Pengkajian dan Penerapan Teknolgi (BPPT)
}

\begin{abstract}
To reduce the organic substance and ammonia in raw water hence raw water from river have to be processed by pretreatment prior to main processing unit. One of the alternatives is biological treatment using submerged biofilter which filled with honeycomb plastic supporting media. Research conducted by operating continuous flow biofilter reactor wich filled with honeycomb plastic supporting media. The size of biofilter reactor is $59 \mathrm{~cm} \times 30 \mathrm{~cm} \times 210 \mathrm{~cm}$, with total volume 371.7 litres. The research was conducting by continuous operation under condition 4 hours, 3 hours, 2 hours and 1 hour retention time.

The result of experiment shows that within the biofilter process under conditions 4 hours, 3 hours, 2 hours and one hour retention time, the removal efficiency of organic substance were $67.27 \%, 53,895,45.70 \%$ and $30.92 \%$ respectively. And the removal efficiency of ammonia under conditions 3 hours, 2 hours and one hour retention time were $73.59 \%$, $67.98 \%$, and $48.74 \%$ respectively. The longer retention time has resulted in higher removal efficiency. By combining biofiltration process with ultra fltration (UF) membrane technology, hence will be got technological alternative of drinking water process which able to degrade an organic matter and ammonia without chemicals instead of convensional process.
\end{abstract}

Kata Kunci : biofiltasi, membran, ultra filtrasi, air minum.

\section{PENDAHULUAN}

\subsection{Latar Belakang Masalah}

Air adalah merupakan kebutuhan yang sangat pokok bagi manusia, terutama untuk memasak dan minum. Dengan pesatnya perkembangan penduduk maka kebutuhan khususnya air bersih untuk masyarakat juga semakin bertambah besar. Masalahnya adalah dengan semakin buruknya kualitas air baku untuk air minum, maka disamping biaya produksinya membesar, hasilnya juga sering kurang baik. Salah satu problem atau masalah yang sering dijumpai pada air minum di dunia akhir-akhir ini yakni timbulnya senyawa yang dinamakan Trihalomethanes atau disingkat THMs, sebagai akibat samping dari proses disinfeksi dengan gas khlor atau senyawa hipokhlorit.

Trihalomethane adalah senyawa organik derivat methan $\left(\mathrm{CH}_{4}\right)$ yang mana tiga buah atom Hidrogen $(\mathrm{H})$ nya diganti oleh atom halogen yakni khlor $(\mathrm{Cl})$, Brom (Br), lodium (I). Beberapa senyawa trialomethane yang umum dijumpai antara lain yakni khloroform $\left(\mathrm{CHCl}_{3}\right)$, dibromokhloromethan $\left(\mathrm{CHBr}_{2} \mathrm{Cl}\right)$, bromoform $\left(\mathrm{CHBr}_{3}\right)$. Jumlah total ke empat senyawa tersebut sering disebut total trihalomethan (TTHM). Selain ke empat senyawa tersebut di atas masih ada beberapa senyawa trihalomenthan lainnya tetapi biasanya kurang stabil.

Adanya senyawa Trihalomethanes dalam air minum diungkapkan pertama kali oleh $\mathrm{J}$. Rook pada sekitar tahun 1972.(JICA:" Water Supply Engineering VOL.I"). Hasil penelitian Rook terhadap kualitas air minum di Roterdam menyatakan bahwa senyawa haloform dalam air minum dengan konsentrasi yang cukup tinggi ditemukan segera setelah proses khlorinasi. Pada tahun 1975 Rook mempresentasikan secara lebih lengkap hasil penelitiannya tentang beberapa faktor yang yang mempengaruhi tebentuknya senyawa Trihalomethane dalam air minum. Rook menyatakan bahwa senyawa THMs terbentuk akibat reaksi antara khlorine dengan senyawa natural seperti "humic substance" yang ada dalam air baku. Setelah itu Environmental Protection Agency (EPA) mempresentasikan hasil penelitian yang dilakukan oleh National Organics Reconnaissance Survey (NORS) yang menyatakan bahwa THMs ditemukan hampir di seluruh air minum (finished water) dan hanya kadang-kadang saja ditemukan dalam air baku air bakunya.

Pada tahun 1976, National Cancer Institute mengumumkan bahwa senyawa khloroform yang merupakan senywa THMs yang paling umum, dengan dosis yang cukup tinggi dapat menyebabkan kanker terhadap tikus. 
Sekarang ini, hampir tidak ada keraguan lagi bahwa senyawa THMs khususnya khloroform adalah senyawa yang sangat potensial dapat menyebabkan kanker.

Banyak para ahli yang berpendapat bahwa sumber air baku yang tercemar baik secara alami ataupun oleh buangan akibat aktifitas kegiatan manusia misalnya buangan rumah tangga maupun industri adalah penyebab terbentuknya senyawa THMs, baik secara langsung atau tidak langsung. Senyawa precursors trihalomethane adalah Senyawasenyawa yang secara potensial dapat menyebabkan terjadinya THMs. Salah satu precursor THMs adalah senyawa humus (Humic and Fulvic Substances) yang secara alami terbentuk akibat proses pelapukan daun daun yang gugur atau sisa tumbuh-tumbuhan yang telah mati oleh aktivitas mikroorganisme. Air limpasan hujan (Run Off) membawa senyawa humus dari daerah hutan atau pertanian, kemudian air limpasan tersebut masuk ke sungai pada bagian hulu, kemudian akan terbawa ke bagian hilir. Di samping itu, air limbah yang berasal dari buangan domestik maupun industri sebagian diolah di pusat pengolahan limbah dan sebagian lagi yang tidak terolah masuk ke badan sungai. Air limbah baik domistik maupun industri mengandung zat organik yang besar.

Air sungai yang mengandung precursor THMs ini, kemudian diolah untuk dijadikan air minum masyarakat di daerah hilir. Kemudian Senyawa precursor THMs tersebut bereaksi dengan senyawa khlor yang digunakan untuk proses disinfeksi sehingga terbentuklah senyawa trihalomethanes dan senyawa halogen organik lainnya. Selain itu, dengan semakin besarnya kandungan amonia dalam air baku maka amonia akan bereakasi dengan khlor membentuk senyawa khloramine yang mempunyai daya disinfeksi yang lebih rendah. Sebagai akibatnya konsumsi senyawa khlor yang digunakan akan bertambah besar, dan dengan semakin besarnya konsentrasi khlor yang digunakan maka kemungkinan akan terbentuknya THMs juga semakin besar.

Salah satu hasil penelitian tentang terbentuknya senyawa halogen organik termasuk THMs dilaporkan oleh Lykins, Mose dan DeMacro (1990). Lykins dan kawan melakukan penelitian dengan menggunakan pilot plant di Jeferson Parish, Lousiana, dengan menggunakan air baku di hilir sungai Mississipi, dengan empat macam bahan disinfektan yakni khlorine, khlorine dioksida, ozone dan khloramine. Konsentrasi total rata-rata halogen organik (TOX) dalam air olahan yakni sekitar 25 $\mathrm{mg} / \mathrm{l}, 15 \mathrm{mg} / \mathrm{l}, 85 \mathrm{mg} / \mathrm{l}, 117 \mathrm{mg} / \mathrm{l}$ dan $263 \mathrm{mg} / \mathrm{l}$, masing-masing untuk proses tanpa disinfeksi, disinfeksi dengan ozone, khlorine dioksida, khloramine dan khlorine.

Dari hasil percobaan tersebut terlihat dengan jelas bahwa disinfeksi dengan khlorine mengakibatkan terbentuknya TOX dengan konsentrasi yang paling tinggi, sedangkan disinfeksi dengan ozone menghasilkan TOX dengan konsentrasi yang paling rendah.

Di negara maju misalnya Amerika, Canada, Eropa dan Jepang, konsentrasi total THMs dalam air minum maksimum yang dibolehkan yakni $0.1 \mathrm{mg} / \mathrm{l}$. Di Jepang misalnya, jika konsentrasi COD (permanganate number) dari air permukaan yang dipakai sebagai air baku lebih besar $12 \mathrm{mg} / \mathrm{l}$ atau warna lebih besar skala 20 atau lebih dibanding dengan air tanah, maka perusahaan air minum harus mulai melakukan pemantauan terhadap THMs dalam air minum.

Di Indonesia, masalah THMs sampai saat ini kelihatannya masih belum banyak disentuh. Perusahaan air minum atau dalam hal ini PAM, kelihatannya masih berkutat mengenai masalah kwantitas dibanding dengan kualitas. Jika kita melihat kondisi air baku untuk PAM khususnya di kota-kota besar, misalnya Jakarta, yang mana kualitas air baku untuk air minum sudah sangat buruk maka seharusnya masalah THMs ini perlu diperhatikan secara serius. Hal ini karena THMs adalah senyawa yang secara potensial dapat menyebabkan kanker (carcinogen).

Dari hasil pemantauan yang dilakukan oleh PAM pada bulan September 2000 terhadap air baku (intake water) di instalasi PAM Cilandak menunjukkan bahwa konsentrasi amoniak bervariasi hingga mencapai sekitar $2,0 \mathrm{mg} / \mathrm{l}$, dimana nilai konsentrasi tersebut telah melampaui ambang batas peruntukkan air baku air minum yakni sebesar $1 \mathrm{mg} / \mathrm{l}$ menurut Kep. Gub. KDKI Jakarta No. 582 th 1995.

Dilihat dari konsentrasi zat pencemar amoniak dalam air baku cukup tinggi, maka PAM di Indonsia khususnya PAM di DKI Jakarta menggunakan senyawa khlor (gas khlor atau kalsium hipoklorit) yang selain untuk proses desinfeksi juga digunakan untuk menghilangkan senyawa logam $\mathrm{Fe}, \mathrm{Mn}$, serta amoniak. Dengan semakin besarnya konsentrasi senyawa amoniak dalam air baku, maka amoniak akan bereaksi dengan khlor menjadi khloramine yang daya desinfeksinya lebih lemah. Hal ini akan mengakibatkan konsumsi khlor akan menjadi lebih besar sehingga biaya operasi menjadi lebih tinggi.

Selain itu dengan semakin besarnya konsentrasi senyawa khlor yang digunakan, maka hasil samping yang dihasilkan seperti terbentuknya senyawa trihalometan dan khlorophenol juga semakin besar. Senyawasenyawa tersebut dapat mengakibatkan penyakit 
kanker (carcinogen). Oleh karena itu zat pencemar amoniak harus dihilangkan.

Untuk mengurangi kadar senyawa organik dan amoniak di dalam air baku air minum maka air sungai harus diolah terlebih dahulu melalui suatu pengolahan pendahuluan sebelum masuk ke unit pengolahan. Salah satu alternatif yakni menggunakan proses biologis dengan sistem biofilter tercelup yang diisi dengan media penyangga dari bahan plastik tipe sarang tawon.

\section{TINJAUAN PUSTAKA}

\subsection{Mekanisme Penguraian Senyawa Polutan Di Dalam Sistem Biofilter}

Di dalam reaktor biofilter, mikroorganisme tumbuh melapisi keseluruhan permukaan media. Pada saat operasi, air yang mengandung senyawa polutan mengalir melalui celah media dan kontak langsung dengan lapisan massa mikroba (biofilm). Biofim yang terbentuk pada lapisan atas media dinamakan zoogleal film, yang terdiri dari bakteri, fungi, alga, protozoa (Eighmy et al, 1983). Metcalf dan Edy mengatakan bahwa sel bakterilah yang paling berperan dan banyak dipakai secara luas di dalam proses pengolahan air buangan, sehingga struktur sel mikroorganisme lainnya dapat dianggap sama dengan bakteri.

Proses yang terjadi pada pembentukan biofilm pada air limbah sama dengan yang terjadi di lingkungan alami. Mikroorganisme yang ada pada biofilm akam mendegradasi senyawa organik yang ada di dalam air. Lapisan biofilm yang semakin tebal akan mengakibatkan berkurangnya difusi oksigen ke lapisan biofilm yang dibawahnya hal ini mengakibatkan terciptanya lingkungan anaerob pada lapisan biofilm bagian atas (Metcalf and Eddy, 1991).

Mekanisme yang terjadi pada reaktor melekat diam terendam adalah (Lim dan Grdy, 1980) :

- Transportasi dan adsopsi zat organik dan nutrien dari fasa liquid ke fasa biofilm

- Transportasi mikroorganisme dari fasa liquid ke fasa biofilm

- Adsorpsi mikroorganisme yang terjadi dalam lapisan biofilm

- Reaksi metabolisme mikroorganisme yang terjadi dalam lapisan biofilm, memungkinkan terjadinya mekanisme pertumbuhan, pemeliharaan, kematian dan lysis sel.

- Attachment dari sel, yaitu pada saat lapisan biofilm mulai terbentuk dan terakumulasi secara kontinu dan gradual pada lapisan biofilm.

- Mekanisme pelepasan (detachment biofilm) dan produk lainnya (by product).
Pertumbuhan mikrooorganisme akan terus berlangsung pada slime yang sudah terbentuk sehingga ketebalan slime bertambah. Difusi makanan dan $\mathrm{O}_{2}$ akan berlangsung sampai ketebalan maksimum. Pada kondisi ini, makanan dan $\mathrm{O}_{2}$ tidak mampu lagi mencapai permukaan padat atau bagian terjauh dari fase cair. Hal ini menyebabkan lapisan biomassa akan terbagi menjadi dua bagian, yaitu lapisan aerob dan lapisan anaerob. Jika lapisan biofilm bertambah tebal maka daya lekat mikroorganisme terhadap media penyangga tidak akan kuat menahan gaya berat lapisan biofilm dan akan terjadi pengelupasan lapisan biomassa. Koloni mikroorganisme yang baru sebagai proses pembentukan lapisan biofilm akan terbentuk pada bagian yang terkelupas ini. Pengelupasan dapat juga terjadi karena pengikisan berlebihan cairan yang mengalir melalui biofilm. Mekanisme proses yang terjadi pada sistem biofilter secara sederhana dapat ditunjukkan seperti pada Gambar 1.

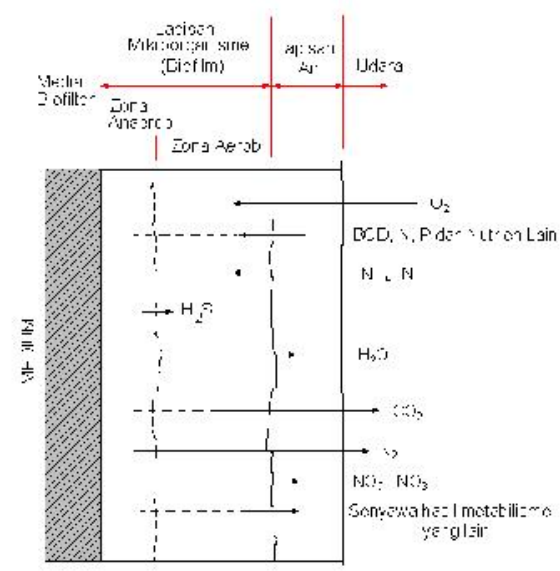

Gambar 1 : Mekanisme proses di dalam sistem biofilm

Pada proses aerobik efisiensi akan menurun dengan bertambahnya lapisan maksimum dan semakin tebalnya lapisan anaerob. Walaupun lapisan biomassa mempunyai ketebalan beberapa milimeter tetapi hanya lapisan luar setebal 0,05-0,15 mm yang merupakan lapisan aerob. Hasil penelitian yang telah dilakukan sebelumnya (Tomlinson dan Snaddon, 1996; Kornegay dan Andrews, 1968; La Moyya, 1976) yang dikutip oleh Winkler,1981 menegaskan bahwa penghilangan substrat oleh lapisan mikroba akan bertambah secara linier dengan bertambahnya ketebalan film sampai dengan ketebalan maksimum, penghilangan tetap konstan dengan bertambahnya ketebalan lebih lanjut. Menurut Bruce (1969) yang dikutip Winkler (1981), ketebalan lapisan aerob 
diperkirakan antara 0,06-2 mm. Penelitian yang telah dilakukan oleh Tomlinson dan Snaddon (1965), Kornegay dan Andrews (1968) ketebalan kritis berkisar antara $0,07-0,15 \mathrm{~mm}$ yang tergantung pada konsentrasi substrat.

\subsection{Proses Biologis untuk menghilangkan Senyawa organik dan amoniak}

Pengolahan air secara biologis merupakan suatau proses penguraian bahan-bahan pencemar, baik yang terlarut maupun yang tidak terlarut menjadi bentuk yang lain berupa gas atau padatan (N.J. Hooran, 1990). Hasil dari transformasi tersebut dipengaruhi oleh kondisi lingkungan pada saat proses berlangsung yaitu kondisi aerobik dan anaerobik (Roswell, 1983).

Proses pengolahan biologis secara aerobik merupakan suatu proses yang membutuhkan oksigen untuk menunjang berlangsungnya proses metabolisme biokimia oleh bakteri dalam peruraian bahan-bahan organik menjadi bentuk yang lebih sederhana yaitu $\mathrm{CO}_{2}, \mathrm{H}_{2} \mathrm{O}$, senyawa-senyawa oksida seperti nitrat, sulfat, phosphat dan terbentuknya massa sel yang baru.

Pada pengolahan secara biologis, pertumbuhan mikroorganisme dapat dilakukan secara melekat pada permukaan media penyangga (attached growth), yakni suatu proses pengolahan dimana senyawa-senyawa organik atau senyawa-senyawa lainnya yang terdapat dalam air diuraikan oleh mikroorganisme yang melekat pada permukaan media penyangga menjadi senyawa yang lebih sederhana serta membentuk biomasa atau selsel baru.

\subsection{Reaktor Biologis Unggun Tetap (Fixed bed Biofilter)}

Struktur reaktor biofilter menyerupai saringan (filter) yang terdiri atas susunan atau tumpukan bahan penyangga yang disebut dengan media penyangga yang disusun baik secara teratur maupun acak di dalam suatu bejana. Fungsi media penyangga adalah sebagai tempat tumbuh dan berkembangnya mikroorganisme yang akan melapisi permukaan media membentuk lapisan massa yang tipis (biofilm). Mikroorganisme ini menguraikan bahan organik yang ada dalam air. Ketebalan lapisan biofilm menyebabkan difusi oksigen berkurang terhadap lapisan terdalam biofilm tersebut sehingga dapat menyebabkan terjadinya kondisi anaerobik pada lapisan permukaan media (Metcalf \& Eddy, 1991). Air yang diolah akan dikontakkan dengan sejumlah mikroba dalam bentuk lapisan film (slime) yang melekat pada permukaan media.
Media penyangga merupakan salah satu kunci pada proses biofilter. Efektifitas dari suatu media tergantung pada :

- Luas permukaan, semakin luas permukaan media maka semakin besar jumlah biomassa per unit volume.

- Volume rongga, semakin besar volume rongga/ruang kosong maka semakin besar kontak antara substrat dalam air buangan dengan biomassa yang menempel

Faktor terpenting yang mempengaruhi pertumbuhan bakteri pada media penyangga adalah kecepatan aliran serta bentuk dan jenis konfigurasi media. Media yang digunakan dapat berupa kerikil, batu pecah (split), media plastik (polivinil chlorida), dan partikel karbon aktif dan lainnya. Media yang sering digunakan pada proses biologis khususnya biofiter adalah media plastik yang terbuat dari PVC (Gabriel Bitton, 1994). Kelebihan dalam penggunaan media plastik ini antara lain :

- Ringan serta mempunyai luas permukaan spesifik besar (luas permukaan per satuan volume) berkisar antara sebesar $85-226$ $\mathrm{m}^{2} / \mathrm{m}^{3}$.

- Volume rongga yang besar dibanding media lainnya (hingga 95\%) sehingga resiko kebuntuan kecil.

$\mathrm{Di}$ dalam reaktor biofilter, mikroorganisme tumbuh melapisi keseluruhan permukaan media dan pada saat beroperasi air mengalir melalui celah-celah media dan berhubungan langsung dengan lapisan massa mikroba (biofilm). Mekanisme perpindahan massa yang terjadi pada permukaan suatu media dinyatakan sebagai berikut :

- Diffusi substansi air buangan dari cairan induk ke dalam massa mikroba yang melapisi media.

- Reaksi peruraian bahan organik maupun anorganik oleh mikroba.

- Diffusi produk peruraian ke luar kecairan induk limbah.

Permukaan media yang kontak dengan nutrisi yang terdapat dalam air buangan ini mengandung mikroorganisme yang akan membentuk lapisan aktif biologis. Disamping itu oksigen terlarut juga merupakan faktor pembentukan lapisan film. Proses awal pertumbuhan mikroba dan pembentukan lapisan film pada media membutuhkan waktu beberapa minggu, yang dikenal dengan "proses pematangan". Pada awalnya tingkat efisiensi penjernihan sangat rendah yang kemudian akan mengalami peningkatan dengan terbentuknya lapisan film (N.J. Horan, 1990). 


\subsection{Lapisan Biomassa}

Lapisan biomassa atau biofilm menurut Siebel (1987) didefinisikan sebagai lapisan sel mikroba yang berkaitan dengan penguraian zat organik yang melekat pada suatu permukaan media.

Kecepatan pertumbuhan lapisan biofilm pada permukaan akan bertambah akibat perkembangbiakan dan adsorpsi yang terus berlanjut sehingga terjadi proses akumulasi lapisan biomassa yang berbentuk lapisan lendir (slime). Pertumbuhan mikroorganisme akan terus berlangsung pada slime yang sudah terbentuk sehingga ketebalan slime bertambah. Difusi makanan dan oksigen akan terus berlangsung sampai tercapai ketebalan maksimum sehingga pada kondisi ini difusi makanan dan oksigen ini tidak mampu lagi mencapai permukaan padatan yang akibatnya lapisan biomassa ini akan terbagi menjadi dua zona yaitu zona aerob dan zona anaerob. Pada kondisi ini mulai terjadi pengelupasan lapisan biomassa yang selanjutnya segera terbentuk koloni mikroorganisme yang baru sehingga pembentukan biofilm akan terus berlangsung. Proses pengelupasan ini juga disebabkan oleh pengikisan cairan yang berlebih yang mengalir melalui biofilm (Winkler, 1981).

Efisiensi penghilangan amoniak pada proses biofilter oleh lapisan biomassa dapat mencapai maksimum bila lapisan tipis di sebelah luar lapisan biomassa telah mencapai ketebalan maksimum untuk kondisi aerobik.

Mekanisme proses penguraian senyawa polutan yang terjadi pada lapisan biofilm secara sederhana dapat diilustrasikan seperti pada Gambar 1, sedangkan ilustrasi dari mekanisme proses penguraian amoniak di dalam biofilm secara sederhana dapat dilihat pada Gambar 2.

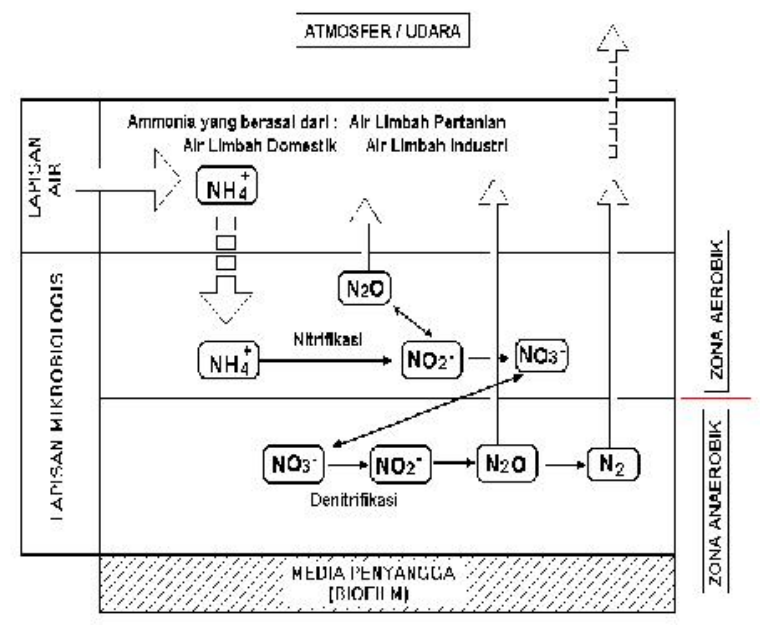

Gambar 2 : llustrasi dari mekanisme proses penguraian amoniak di dalam biofilm
Lapisan terluar media penyangga adalah lapisan tipis zona aerobik, senyawa amoniak dioksidasi dan diubah ke dalam bentuk nitrit. Sebagian senyawa nitrit ada yang diubah menjadi gas dinitrogen oksida $\left(\mathrm{N}_{2} \mathrm{O}\right)$ dan ada yang diubah menjadi nitrat. Proses yang terjadi tersebut dinamakan proses nitrifikasi.

Semakin lama, lapisan biofilm yang tumbuh pada media penyangga tersebut semakin tebal sehingga menyebabkan oksigen tidak dapat masuk ke dalam lapisan biofilm yang mengakibatkan terbentuknya zona anaerobik. Pada zona anaerobik ini, senyawa nitrat yang terbentuk diubah ke dalam bentuk nitrit yang kemudian dilepaskan menjadi gas nitrogen $\left(\mathrm{N}_{2}\right)$. Proses demikian tersebut dinamakan proses denitrifikasi.

\section{PENGOLAHAN AIR DENGAN PROSES BIOFILTRASI}

\subsection{Proses Pengolahan}

Penelitian dilakukan dengan menggunakan suatu reaktor berskala pilot plant. Reaktor ini mempunyai ukuran tinggi $210 \mathrm{~cm}$, panjang 59 $\mathrm{cm}$ dan lebar $30 \mathrm{~cm}$ dengan volume 372 liter dan dibuat dari bahan fiber glass. Reaktor biofilter terdiri dari bak pengendapan awal, bak biofilter yang terdiri dari media sarang tawon dan pengendapan akhir. Bioreaktor ini dilengkapi dengan pipa inlet dan pipa outlet yang terletak pada kedua sisi reaktor. Pada bagian bawah reaktor terdapat ruang lumpur yang berfungsi sebagai tempat pengendapan yang dapat digunakan untuk mengeluarkan lumpur yang mengendap (Gambar 3).

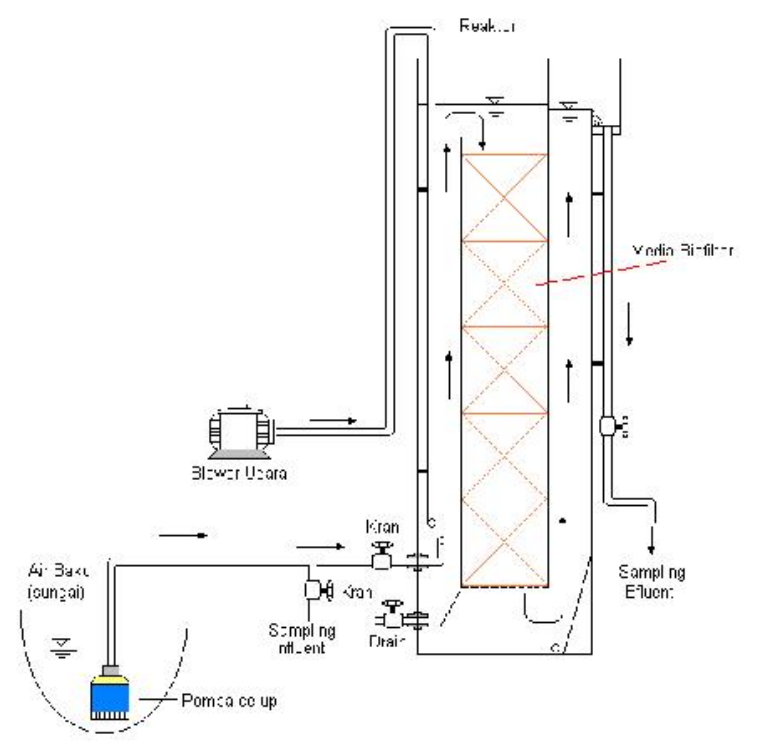

Gambar 3 : Pengolahan air minum dengan proses biofiltrasi. 
Pengaliran air yang akan diolah dilakukan dengan terus-menerus (continues flow) dan aliran di dalam media biofilter dilakukan adalah secara down flow (dari atas ke bawah). Proses yang terjadi pada bioreaktor adalah proses aerobik sehingga pemberian oksigen dilakukan dengan cara menggunakan pompa (blower) udara yang diinjeksikan ke dalam reaktor.

Media penyangga yang dipergunakan adalah sarang tawon (cross flow ) yang terbuat dari plastik. Ukuran modul tiap media adalah 30 $\times 25 \times 30 \mathrm{~cm}$. Penelitian ini menggunakan 5 media dengan keseluruhan tinggi $1,5 \mathrm{~m}$.

Pada penelitian ini dilakukan variasi waktu tinggal hidrolis, yaitu 1 jam, 2 jam, 3 jam dan 4 jam untuk melihat kemampuan bioreaktor dalam menyisihkan zat organik. Pemilihan waktu tinggal hidrolis ini disesuaikan dengan kriteria pengolahan pendahuluan (pretreatment), yaitu $0,5-4$ jam (CR. Schultz \& DA Okun, 1984). Penelitian dilanjutkan dengan melakukan sirkulasi yaitu mengalirkan kembali air olahan yang ada pada bak pengendapan akhir menggunakan pompa sirkulasi ke bak biofilter. Perbandingan resirkulasi untuk media plastik adalah $1-2 \mathrm{Q}$. Penentuan resirkulasi dilakukan setelah diperoleh waktu tinggal hidrolis yang optimum.

\subsection{Pembiakan Mikroorganisme (Seeding)}

Pembiakan (seeding) mikroorganisme dilakukan secara alami yaitu dengan cara mengalirkan air baku Sungai Krukut yang akan diolah secara terus menerus ke dalam bioreaktor yang telah terisi media sarang tawon sampai terbentuknya lapisan biofilm yang melekat pada media dengan waktu tinggal hidrolik 6 (enam) jam. Pertumbuhan mikroorganisme ini juga didukung oleh pemberian oksigen secara terus menerus dengan menginjeksikan oksigen ke dalam reaktor melalui alat pompa udara.

Pada awal penelitian selama 2 (dua) minggu pertama dilakukan pengamatan secara fisik. Pada tahap ini proses pengolahan belum berjalan dengan baik karena mikroorganisme yang ada pada bioreaktor belum tumbuh secara optimal. Setelah proses berjalan selama 2 (dua) minggu mikroorganisme sudah mulai tumbuh dan berkembang biak serta membentuk lapisan lendir (biofilm) pada permukaan media. Lapisan biofilm in mengandung mikroorganisme yang akan menguraikan zat pencemar organik yang terdapat pada air baku.

Pertumbuhan mikroorganisme diamati dengan mengukur penghilangan senyawa organik (angka Permanganat, $\mathrm{KMnO} 4$ ) di dalam bioreaktor setelah dua minggu proses berjalan.
Pengukuran dilakukan setiap hari sampai penghilangan zat organik menjadi relatif stabil.

Efisiensi penghilangan zat organik pada awal pengoperasian cenderung kecil, yaitu $12,20 \%$. Hal ini dapat disebabkan pada awal operasi pertumbuhan mikroba optimal dan lapisan biofilm masih tipis. Pada hari ke-11 penghilangan zat organik telah mencapai $50 \%$. Peningkatan efisiensi ini disebabkan mikroorganisme pada reaktor telah tumbuh dan berkembang biak dan membentuk lapisan biofilm yang lebih tebal dari sebelumnya sehingga zat organik yang ada dalam air baku diuraikan.

Penurunan konsentrasi senyawa organik di dalam influen dan efluen serta efisiensi penghilangan senyawa organik selama proses seeding ditunjukkan seperti pada Gambar 4.

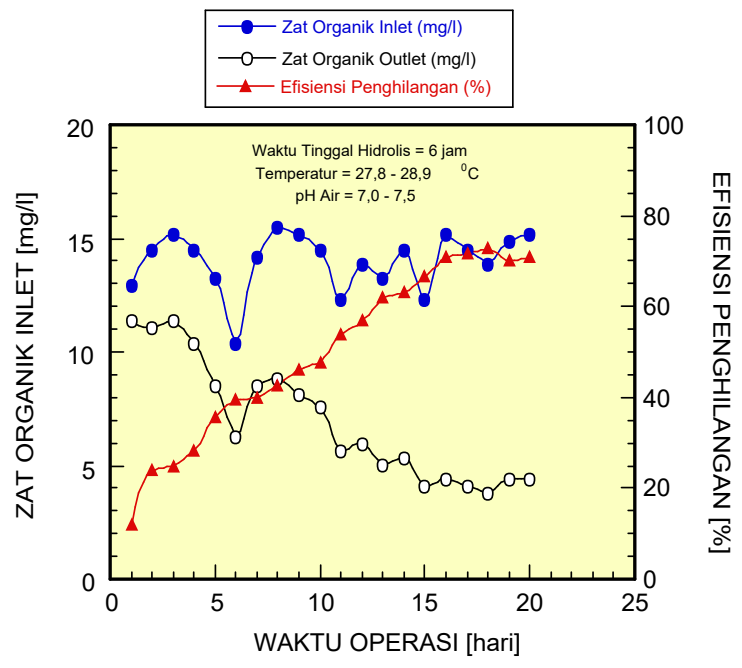

Keterangan

Temperatur Air : 27,8-28,9 ${ }^{\circ} \mathrm{C} ; \mathrm{pH}$ air : 7,0 - 7,5 Konsentrasi zat organik diukur dengan angka permanganat.

Gambar 4 : Penurunan konsentrasi senyawa organik di dalam influen dan efluen serta efisiensi penghilang-an senyawa organik selama proses seeding.

Dari gambar tersebut dapat dilihat bahwa pada operasi hari ke-16 sampai dengan hari ke-20, penghilangan zat organik meningkat dari hari sebelumnya dan cenderung stabil, yaitu antara $70,21 \%-72,73 \%$.

Gambar 4 menunjukkan bahwa efisiensi penurunan konsentrasi zat organik $\left(\mathrm{KMnO}_{4}\right)$ dari ke-1 sampai ke-20 mengalami peningkatan dan menjadi stabil. Hal ini menunjukkan bahwa proses awal pertumbuhan mikroba dan pembentulkan lapisan biofilm pada media membutuhkan waktu beberapa minggu, yang dikenal dengan proses pematangan (Rittman, et al, 1988). Adanya penghilangan zat organik yang cukup besar tersebut menunjukkan bahwa 
mikroorganisme telah tumbuh melekat pada media dan membentuk lapisan biofilm.

\subsection{Penghilangan Senyawa Organik}

\section{A. Pengaruh Waktu Tinggal Hidrolis terhadap Efisiensi Penghilangan Senyawa Organik.}

Setelah proses pembiakan mikroba telah stabil, debit air diatur agar waktu tinggal hidrolis (WTH) di dalam reaktor menjadi 4 (empat) jam, 3 Itiga) jam, 2 (dua) jam dan 1 (satu) jam, untuk mengetahui pengaruhnya terhadap efisiensi penghilangan senyawa organik.

Hasil penelitian ditunjukkan seperti pada dan Gambar 5.

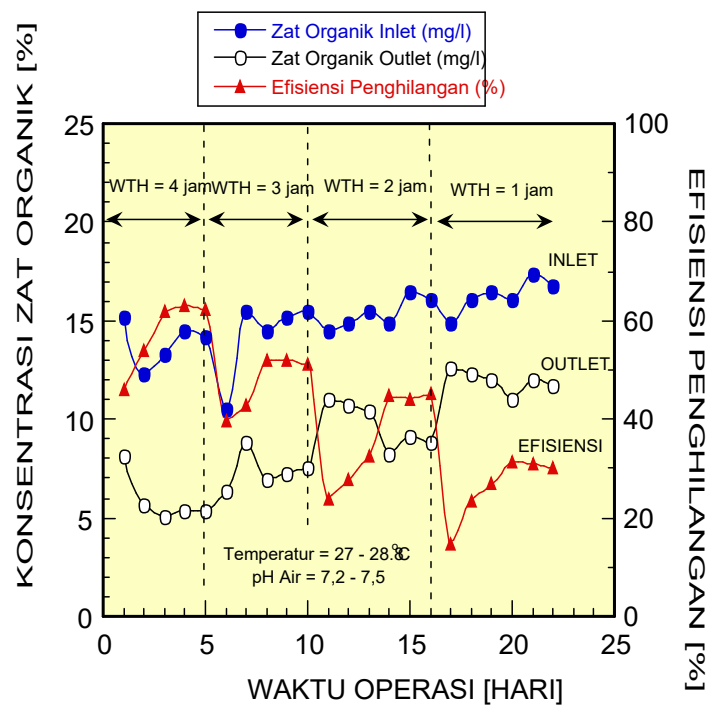

Gambar 5 : Pengaruh waktu tinggal hidrolik (WTH) terhadap penurunan konsentarsi zat organik serta efisiensi penghilangan pada proses biofilter tercelup.

Dari hasil penelitian tersebut terlihat bahwa setelah waktu tinggal diubah menjadi empat jam efisiensi penghilangan zat organik sekitar $46 \%$ dan menjadi stabil setelah tiga hari operasi yakni efisiensi penghilangan naik menjadi sekitar 62 $\%$. Fenomena yang sama juga terjadi setelah waktu tinggal diubah menjadi tiga jam, dua jam dan satu jam, yakni efisiensi penghilangan zat organik turun dan perlahan-lahan efisiensi penghilangan zat organik naik lagi dan menjadi stabil stelah 3-4 hari operasi. Hal ini kemungkinan disebabkan karena mikroorganisme memerlukan waktu adaptasi terhadap perubahan beban organik yang masuk ke dalam reaktor.

Dari hasil tersebut diketahui bahwa semakin pendek waktu tinggal hidrolis yaitu dari 4 jam menjadi 1 jam, efisiensi penghilangan zat organik (KMnO4) pada kondisi stabil juga menjadi semakin kecil yakni dari 64,29\% menjadi $30,92 \%$.

Hal ini disebabkan semakin singkatnya waktu kontak antara bahan organik dengan mikroorganisme pada lapisan biofilm, sehingga semakin sedikit kesempatan mikroba untuk dapat memanfaatkan zat organik tersebut untuk proses metabolisme tubuhnya.

\section{B. Pengaruh Beban Organik Terhadap Efisiensi Penghilangan Zat Organik}

Beban organik adalah jumlah senyawa organik yang masuk kedalam reaktor per satuan volume media per satuan waktu, yang dinyatakan sebagai berat organik persatuan volume media perhari. Dari hasil percobaan didapatkan hubungan antara beban organik dengan efisiensi penghilangan zat organik seperti ditujukkan pada Gambar 6 .

Dari hasil tersebut terlihat bahwa dengan beban organik antara 0,2-1,5 $\mathrm{kg} / \mathrm{m}^{3}$.hari, hubungan antara beban organik dengan efisiesi penghilangan organik merupakan suatu hubungan yang linier.

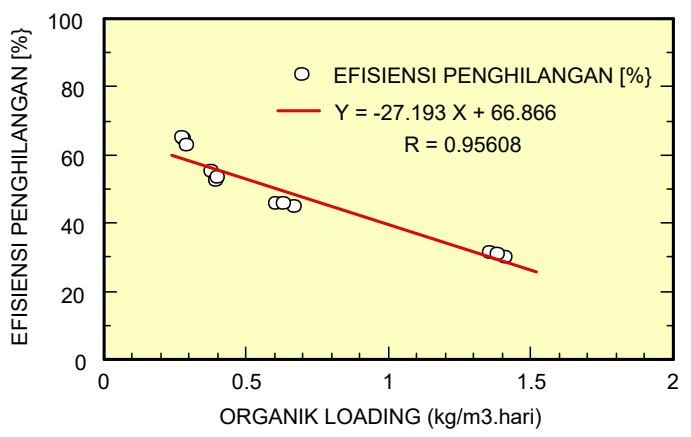

Gambar 6 : Grafik Hubungan Antara Beban Organik dengan Efisiensi.

Dengan menggunakan program Keleida Graf, Machintosh, persamaan hubungan antara beban organik dengan efisiensi penghilangan zat organik didapatkan persamaan sebagai berikut yakni :

$$
Y=27,193 X+66,866
$$

dimana :

$$
\begin{gathered}
Y=\text { Efisiensi penghilangan senyawa } \\
\text { organik (\%). } \\
X=\text { Beban organik ( } \mathrm{kg} / \mathrm{m}^{3} \text { media.hari). }
\end{gathered}
$$

\subsection{Penghilangan Amoniak}
A. Pengaruh Waktu Tinggal Hidrolis terhadap Efisiensi Penghilangan Senyawa Amoniak.


Setelah proses pembiakan mikroba dilakukan, selanjutnya waktu tinggal hidrolis (WTH) di dalam reaktor diubah menjadi 4 (empat) jam, 3 (tiga) jam, 2 (dua) jam dan satu jam. Perubahan konsentrasi amoniak sebelum dan sesudah pengolahan serta efisiensi penghilangan amoniak di dalam reaktor biofilter pada selang waktu tinggal hidrolis (WTH) empat jam sampai dengan satu jam secara lengkap ditunjukkan seperti pada Gambar 7. Sedangkan perubahan konsentrasi nitrit dan nitrat selama proses pengolahan ditujukkan seperti pada Gambar 8.

Dari hasil percobaan tersebut di atas, perhitungan tingkat efisiensi dengan ini didapat hasil efisiensi yang cukup tinggi. Hal ini menunjukkan bahwa proses penguraian amoniak pada saat nitrifikasi selain dilakukan oleh mikroorganisme autotrof juga dilakukan oleh mikroorganisme heterotrof untuk mensintesa sel.

Dari hasil percobaan tersebut juga menunjukkan bahwa efisiensi penurunan amoniak berdasarkan variasi waktu tinggal hidrolis berkisar antara 48,74 \% - $73.59 \%$. Dengan adanya efisiensi penurunan tersebut menunjukkan bahwa di dalam bioreaktor lekat bermedia sarang tawon terjadi proses nitrifikasi.

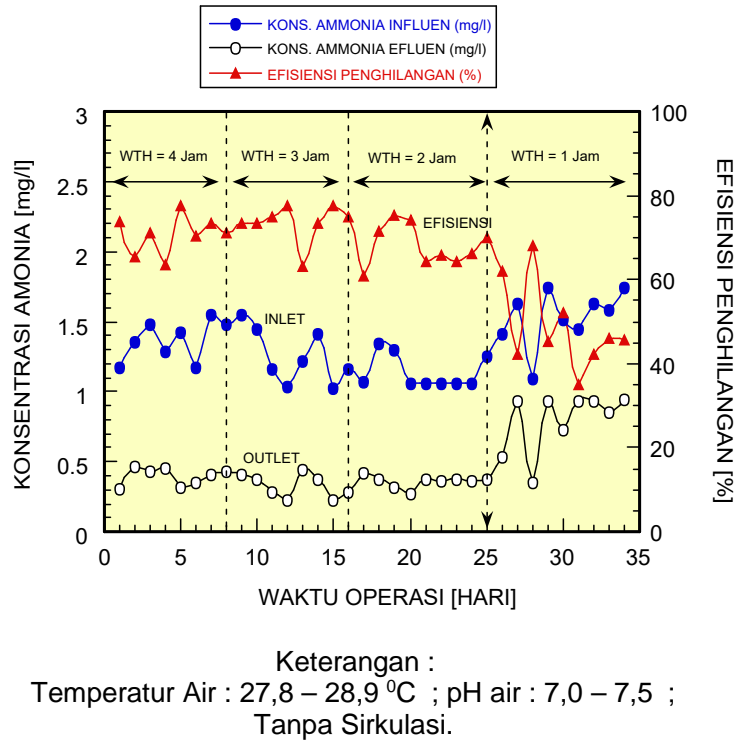

Gambar 7 : Grafik konsentrasi amoniak sebelum dan sesudah pengolahan serta efisiensi penghilangan.

Pada pengolahan dengan pengkondisian waktu tinggal hidrolis 1 jam efisiensi penurunan sebesar $45.11 \%$, untuk waktu tinggal 2 jam menunjukkan efisiensi sebesar $66.68 \%$, untuk waktu tinggal 3 jam efisiensi sebesar $75.30 \%$.

Dari grafik terlihat bahwa efisiensi penurunan amoniak ini semakin mengalami peningkatan seiring dengan bertambahnya waktu tinggal di dalam reaktor, hal ini dikarenakan semakin lama waktu kontak antara air buangan dengan lapisan biomaassa yang tumbuh di media akan semakin banyak amoniak yang terurai. Tetapi untuk waktu tinggal 4 jam, efisiensi mengalami penurunan sebesar $71.61 \%$.

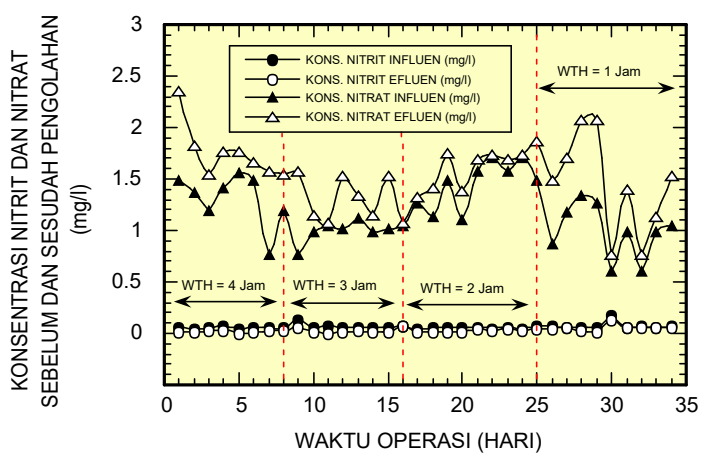

Keterangan : Temperatur Air : $27,8-28,9^{\circ} \mathrm{C} ; \mathrm{pH}$ air : 7,0 7,5 ; Tanpa Sirkulasi.

Gambar 8 : Grafik perubahan konsentrasi nitrit dan nitrat sebelum dan sesudah pengolahan.

Penurunan konsentrasi amoniak di dalam air menyebabkan konsentrasi nitrat di dalam air olahan menjadi lebih besar. Perubahan konsentrasi Nitrit dan Nitrat sebelum dan sesudah pengolahan ditujukkan seperti pada Gambar 8

Dilihat dari penurunan konsentrasi amoniak dan peningkatan konsentrasi nitrat menunjukkan bahwa di dalam biofilter terjadi proses nitrifikasi. Bakteria yang terlibat dalam proses ini adalah bakteri autotrof yang berperan dalam proses nitrifikasi, sedangkan bakteri heterotrof berperan dalam penguraian beban organik. Walaupun bakteri autotrof berperan dalam proses nitrifikasi, proses ini dapat juga terjadi dengan adanya bakteri heterotrof (Verstraete \& Alexander, 1972).

Menurut Metcalf \& Eddy (1991), yang mengatakan bahwa bakteri heterotrof menggunakan substrat organik sebagai sumber energinya, sedangkan bakteri autotrof menggunakan senyawa $\mathrm{CO}_{2}$ dan $\mathrm{HCO}_{3}$ - sebagai sumber energi yang diperoleh dari hasil oksidasi bakteri heterotrof.

Proses nitrifikasi yang terjadi ini menurut Gardy \& Lim (1980), adalah suatu proses pengubahan dari $\mathrm{NH}_{4}-\mathrm{N}$ menjadi $\mathrm{NO}_{2}-\mathrm{N}$ yang kemudian menjadi $\mathrm{NO}_{3}-\mathrm{N}$ yang dilakukan oleh bakteri autotropik dan heterotropik. Pengubahan $\mathrm{NH}_{4}-\mathrm{N}$ menjadi $\mathrm{NO}_{2}-\mathrm{N}$ dilakukan oleh bakteri nitrosomonas dan selanjutnya $\mathrm{NO}_{2}-\mathrm{N}$ yang terbentuk diubah menjadi $\mathrm{NO}_{3}-\mathrm{N}$ oleh bakteri nitrobacter. Kedua jenis bakteri di atas 
berlangsung dalam keadaan aerob sehingga memerlukan konsentrasi oksigen yang cukup untuk sumber energi dalam menunjang proses metabolisme, dan juga proses nitrifikasi merupakan suatu proses aerob sehingga keberadaan oksigen sangat penting dalam proses ini (Benefield \& Randal, 1980).

Konsentrasi oksigen terlarut yang diperlukan agar proses nitrifikasi dapat berjalan dengan baik yaitu jika DO minimumnya $>1 \mathrm{mg} / \mathrm{l}$ (Benefield \& Randall, 1980), tetapi bila konsentrasi oksigen terlarut dibawah $1 \mathrm{mg} / \mathrm{l}$ maka proses nitrifikasi menjadi lambat (Metcalf \& Eddy, 1991).

Sedangkan konsentrasi nitrit $\left(\mathrm{NO}_{2}-\mathrm{N}\right)$ dan nitrat $\left(\mathrm{NO}_{3}-\mathrm{N}\right)$ mengalami perubahan. Senyawa nitrit merupakan senyawa peralihan yang terjadi dalam siklus biologis. Senyawa ini dihasilkan dari suatu proses oksidasi $\mathrm{NH}_{4}-\mathrm{N}$, tetapi sifatnya tidak stabil karena pada kondisi aerobik selama nitrit terbentuk dengan cepat nitrit dioksidasi menjadi nitrat oleh bakteri nitrobacter, oleh karena itu senyawa nitrit ditemukan dalam jumlah yang kecil.

Peningkatan konsentrasi nitrat (-N) dapat disebabkan adanya oksigen yang dialiri secara terus menerus ke dalam reaktor, sehingga dapat menyebabkan pembentukan nitrat, seperti reaksi dibawah ini :

$$
\begin{aligned}
& \mathrm{NO}_{2}^{-}+1 / 2 \mathrm{O}_{2} \Rightarrow \mathrm{NO}_{3}^{--} \\
& \mathrm{NH}_{4}{ }^{-}+2 \mathrm{O}_{2} \Rightarrow \mathrm{NO}_{3} 3^{--}+2 \mathrm{H}^{+}+\mathrm{H}_{2} \mathrm{O}
\end{aligned}
$$

Berdasarkan U.S. EPA (1975), pH optimum untuk aktivitas bakteri nitrosomonas dan nitrobacter agar dapat berjalan dengan optimal yaitu antara 7,5 - 8,5. Kondisi pH antara 7,0 7,5 menyebabkan peran bakteri nitrosomonas dalam proses nitrifikasi belum berjalan secara optimal, begitu pula dengan bakteri nitrobacter yang mengubah nitrit menjadi nitrat.

\section{B. Laju Pembebanan Amoniak $\left(\mathrm{NH}_{4}-\mathrm{N}\right)$}

Laju pembebanan digunakan untuk mengetahui jumlah beban air buangan yang diolah pada reaktor. Dalam percobaan ini, perhitungan laju beban senyawa amoniak dapat dilakukan dengan menggunakan persamaan seperti yang ditunjukkan pada sub bab III.2.F.

Berdasarkan percobaan yang telah dilakukan di atas, dapat dihitung besarnya beban amoniak (ammonia loading) dihubungkan dengan besarnya efisiensi penghilangan amoniak.

Dari hasil perhitungan maka dapat dibuat grafik hubungan antara efisiensi penghilangan $\mathrm{NH}_{4}-\mathrm{N}(\%)$ dengan laju beban $\mathrm{NH}_{4}-\mathrm{N}\left(\mathrm{gr} / \mathrm{m}^{3}\right.$. Hari) seperti ditunjukkan pada Gambar 9.

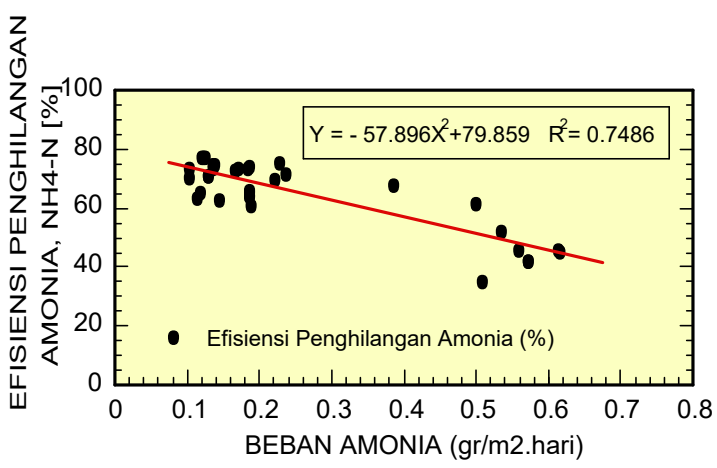

Gambar 9 : Grafik hubungan antara Laju Pembebanan dengan Efisiensi Penghilangan Amoniak di dalam reaktor biofilter tercelup.

Dari Gambar 9 tersebut di dapatkan persaman hubungan antara beban amoniak dengan efisiensi penghilangan amoniak yang ditunjukkan dengan persamaan $: Y=-57,896 X+$ 79,859 di mana $Y$ adalah efisiensi penghilangan amoniak (\%), dan $\mathrm{X}$ adalah beban amoniak yang dinyatakan dalam $\mathrm{gr}$ amoniak $/ \mathrm{m}^{2}$ media per hari, dengan nilai $R$ (regresi) dengan harga $R^{2}=$ 0,7486 . dari hasil tersebut terlihat bahwa dengan beban amoniak sebesar $0,1-0,7 \mathrm{gr} / \mathrm{m}^{2}$.hari di dapatkan efisiensi penghilangan amoniak antara $40-75 \%$.

\subsection{Penghilangan Zat Besi}

Berdasarkan hasil percobaan tersebut di atas dengan menggunakan proses biofilter dengan media plastik tipe sarang tawon dapat juga menghilangkan zat besi yang ada di ada air dengan cukup baik. Konsentrasi zat besi yang ada di dalam air sungai selama percobaan berkisar antara 0,83 $\mathrm{mg}$ per liter sanpai dengan 3,54 mg per liter. Pengaruh waktu tinggal hidrolik (WTH) terhadap penurunan konsentarsi zat besi selama percobaan secara lengkap ditunjukkan seperti pada Gambar 10.

Secara umum semakin kecil waktu tinggal hidrolik di dalam reaktor maka efisiensi penghilangan zat bsi juga semakin kecil. Dengan waktu tinggal hidrolik (WTH) 4 jam efisiensi penghilangan zat besik berkisar antara 55 - $74 \%$, untuk WTH 3 jam efisiensi penghilangan berkisar antara $55-70 \%$, untuk WTH 2 jam efisiensi penghilangan $40-61 \%$, sedangkan untuk WTH 1 jam efisiensi penghilangan zat besi berkisar antara $18-39 \%$.

Zat besi adalah salah satu senyawa yang dapat bereaksi dengan senyawa khlor, oleh karena itu di dalam proses pengolahan air minum jika konsentrasi zat besi cukup tinggi maka konsumsi senyawa khlor menjadi besar pula, dan akibatnya selain biaya pengolahan bertambah besar karena konsumsi khlor 
bertambah maka kemungkinan terbentuknya senyawa trihalomethan juga semakin besar pula.

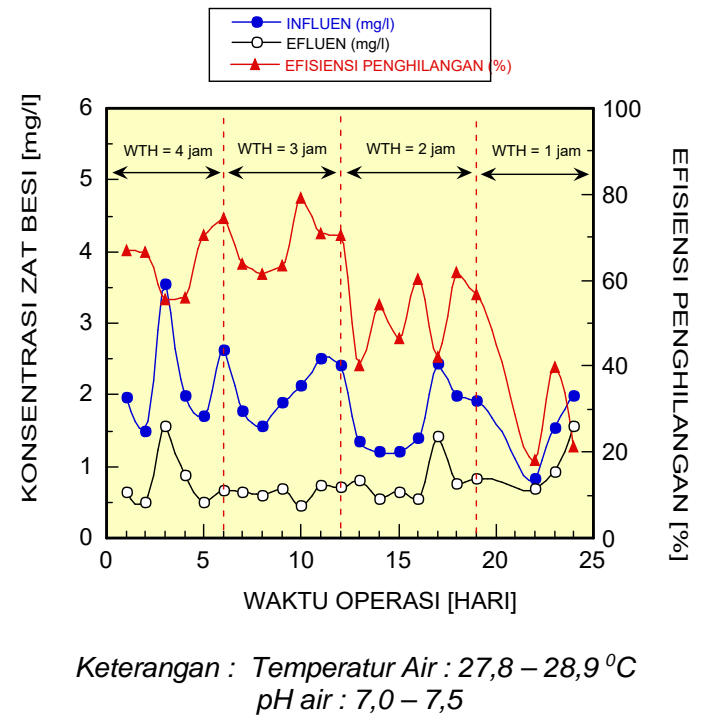

Gambar 10 : Grafik konsentrasi zat besi sebelum dan sesudah pengolahan serta efisiensi penghilangan.

\subsection{Identifikasi Mikroorganisme}

Di dalam proses pengolahan secara biologis, mikroorganisme merupakan faktor yang penting terhadap berlangsungnya proses biologis baik dalam penurunan kandungan bahan organik maupun dalam proses nitrifikasi. Identifikasi mikroorganisme pada bioreaktor lekat bermedia sarang tawon ini dimaksudkan untuk mengetahui jenis mikroorganisme yang berperan dalam penurunan bahan organik dan proses nitrifikasi. Hasil identifikasi mikroorganisme yang terdapat di dalam rekator biofilter tercelup ditunjukkan seperti pada Tabel 1.

Tabel 1: Mikroorganisme yang terdapat di dalam Reaktor Biofilter tercelup

\begin{tabular}{|c|l|}
\hline No & Jenis Mikroorganisme \\
\hline 1 & Bacillus Subtilis \\
\hline 2 & Proteus Vulgaris \\
\hline 3 & Clostridium Tetani \\
\hline 4 & Escherichia Coli \\
\hline 5 & Nitrosomonas \\
\hline 6 & Nitrobacter \\
\hline
\end{tabular}

Sumber : Lab. Mikrobiologi FK Universitas Trisakti.

Dari tabel tersebut dapat terlihat bahwa, jenis mikroorganisme yang ditemukan pada pengolahan biologis dengan menggunakan reaktor biofilter tercelup menggunakan media sarang tawon diantaranya adalah nitrosomonas dan nitrobacter. Dengan adanya kedua jenis mikroorganisme tersebut menunjukkan bahwa proses nitrifikasi dapat terjadi pada pengolahan biologis ini.

\section{PENGOLAHAN AIR MINUM DENGAN KOMBINASI PROSES BIOLOGIS DAN TEKNOLOGI MEMBRANE}

\subsection{Teknologi Membrane di dalam Pengolahan Air}

Perkembangan teknologi dalam pengolahan air telah berkembang demikian pesatnya, yang mana diharapkan dapat menjadi jawaban untuk sebagian dari permasalahan yang ada dalam pengolahan air bersih. Salah satu teknologi yang dikembangkan adalah teknologi penyaringan atau filtrasi dengan menggunakan membran.

Teknologi menggunakan membran sebenarnya bukanlah suatu teknologi yang baru ditemukan, karena membran itu sendiri telah digunakan semenjak lebih dari 50 tahun yang lalu. Adapun jenis membran yang tersedia saat ini dibagi menjadi 4 kelompok besar disesuaikan dengan ukuran dari tingkat penyaringan atau sering disebut dengan istilah 'Filtration degree".

Tingkat-tingkat penyaringan yang dimaksud adalah sebagai berikut :
* Micro Filtration (MF)
* Ultra Filtration (UF)
* Nano Filtration (NF)
- Hyper Filtration / Reverse Osmosis (RO)

Distribusi ukuran partikel yang dapat dipisahkan sesuai dengan tingkatan proses filtrasi dapat dilihat pada Gambar 11.

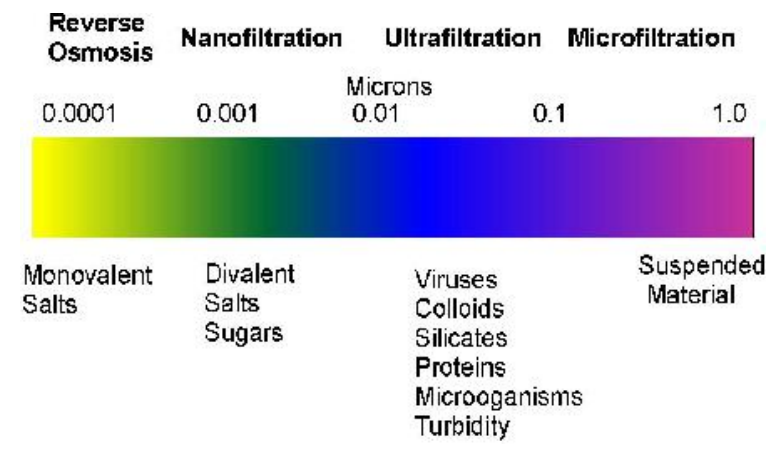

Gambar 11 : Distribusi ukuran partikel yang dapat dipisahkan sesuai dengan tingkatan proses filtrasi.

Sesuai dengan nama dan tingkatan dari 'Filtration Degree", diharapkan akan didapatkan air dengan tingkat kebersihan tertentu pula. Misalnya pada Micro Filtration / MF dengan 
derajad penyaringan (Filtration Degree) sekitar 1 micron, diharapkan sebagian besar dari padatan tersuspensi (suspended material) akan tersaring. Dan sudah bukan menjadi suatu hal yang baru bahwa dengan menggunakan teknologi membran ini telah dimungkinkan merubah air laut menjadi air tawar, yaitu dengan menggunakan membran Reverse Osmosis (RO).

\subsection{Peran Serta Teknologi Membran dalam Pengolahan Air Minum}

Seperti telah dijelaskan di atas bahwa baku mutu air baku yang semakin memburuk mengharuskan kita untuk mencari teknologi alternatif guna menjawab permasalahanpermasalahan yang ada. Salah satu masalah yang cukup serius adalah semakin buruknya kualitas air baku akibat pencemaran limbah organik misalnya oleh air limbah domestik. Dengan kondisi air baku seperti tersebut di atas tidak dapat diatasi dengan pengolahan air minum secara konvensional. Salah satu alternatif teknologi di masa depan adalah menggunakan kombinasi proses biologis misalnya biofilter dengan teknologi membran ultra filtrasi (UF).

Dari sekian banyak applikasi dengan menggunakan teknologi membran, beberapa di antaranya adalah :

* Pengolahan air permukaan.

* Pengolahan air permukaan yang tercemar.

* Daur Ulang Air Limbah

Pengolahan air permukaan yang sering digunakan saat ini adalah dengan menggunakan proses pengendapan kimia dan filter pasir cepat seperti yang terlihat pada Gambar 12 .

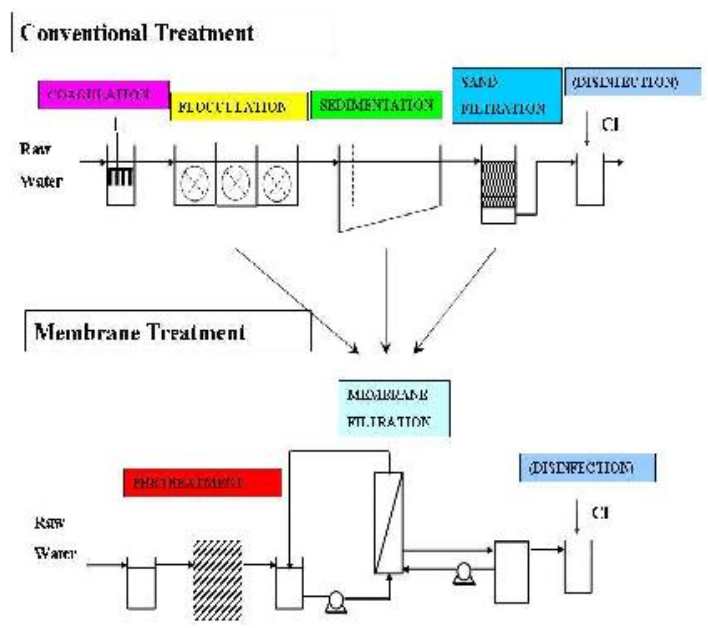

Gambar 12 : Perbandingan proses pengolahan air minum secara konvensional dan proses dengan teknologi membrane ultra filtrasi.
Dari gambar di atas dapat dilihat bahwa sistem dengan menggunakan teknologi membran ultra filtrasi dapat memberikan suatu alternatif bagi pengolahan air minum yang sekaligus memberikan manfaat-manfaat antara lain:

- konsistensi dan mutu air yang dihasilkan.

- luasan area yang jauh lebih kecil (hanya sekitar $25-40 \%$ )

- sistem yang jauh lebih kompak dan dapat dilakukan secara otomatis.

\subsection{Pengolahan Air Minum dengan Proses Biofiltrasi dan Ultra Filtrasi}

Dengan menggabungkan proses biofiltrasi seperti yang telah dilakukan pada percobaan di atas dengan teknologi membran ultra filtrasi (UF) maka akan didapatkan suatu alternatif teknologi pengolahan air minum yang dapat menurunkan kandungan zat organik dan amoniak tanpa menggunakan bahan kimia seperti pada proses konvesional. Ilustrasi proses pengolahan air minum dengan kombinasi proses biofiltrasi dan proses ultra filtrasi dapat dilihat sepertri pada Gambar 13.

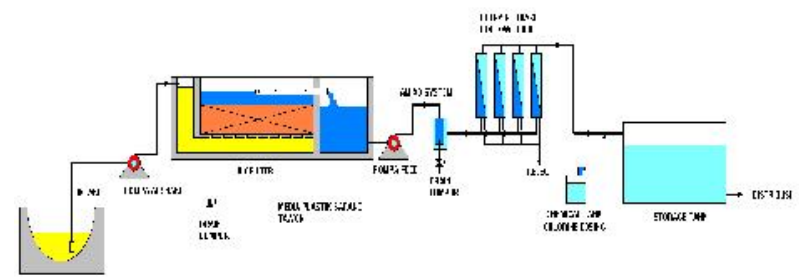

Gambar 13 : llustrasi proses pengolahan air minum dengan kombinasi proses biofilter dan proses filtrasi membrane.

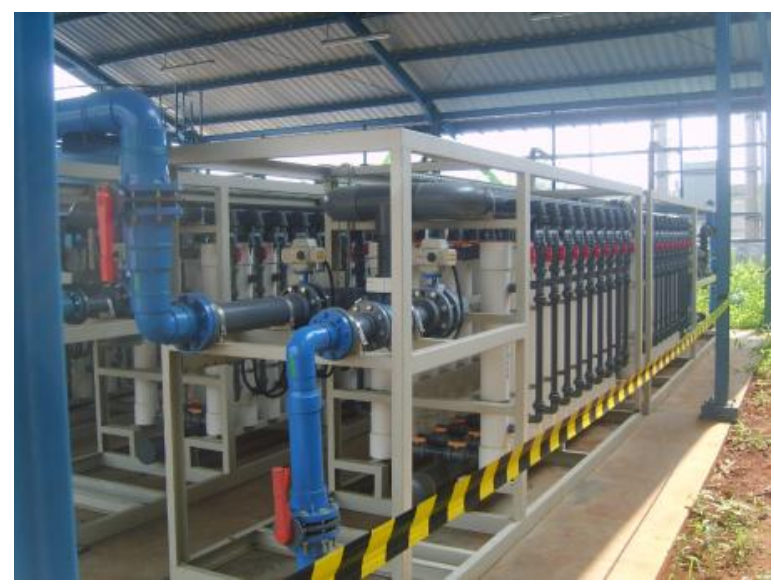

Gambar 14 : Unit Pengolahan Air Minum dengan Proses Ultrafiltrasi, Kapasitas $180 \mathrm{~m}^{3}$ per jam.

Air baku dari saluran intake dipompa ke reaktor biofilter dengan menggunakan pompa air baku. Reaktor biofilter diisi dengan media biofilter dari 
bahan plastik tipe sarang tawon. Di dalam reaktor biofilter tersebut senyawa polutan yang ada di dalam air baku misalnya zat organik, amoniak, zat besi, mangan, deterjen dan senyawa polutan lain dapat diuraikan secara biologis. Selain itu padatan tersuspensi yang ada di dalam air baku dapat diendapakan. Air yang keluar dari biofilter selanjutnya di tampung ke bak penampung, selanjutnya dipompa ke automatik filter yang dapat menyaring kontoran sampai 10-50 mikron. Dari filter automatik air dilairkan ke unit ultra filtrasi yang dapat menyaring sampai ukuran 0,01 mikron.

Unit ultra filtrasi menggunakan modul membrane tipe hollow fiber. Air yang keluar dari unit ultra filtrasi dilairkan ke bak penampung air olahan sambil diinjeksi dengan larurtan kaporit untuk proses disinfeksi dan selanjutnya dilairkan ke sistem distribusi.

Dengan sistem kombinasi biofiltrasi dan ultra filtrasi mempunyai beberapa kelebihan antara lain adalah :

- Penggunaan proses biofiltrasi dapat menghilangkan senyawa polutan yang tidak bisa dihilangkan dengan proses konvensional misalnya, zat organik, amoniak, deterjen, pestisida, dll. Senyawa tersebut dapat diuraikan dengan proses biologis secara alami (natural).

- Tanpa menggunakan bahan koagulan dan flokulan. Dalam hal ini bahan yang digunakan hanya larutan kaporit untuk mendapatkan konsentrasi sisa klor yang cukup agar tidak terjadi rekontaminasi.

- Dengan proses ultra filtrasi dapat dihasilkan air olahan dengan kualitas yang sangat baik dan stabil.

- Bentuknya lebih kompak sehingga luas area yang dibutuhkan lebih kecil.

- Sangat fleksibel jika ada penambahan kapasitas.

\section{KESIMPULAN}

Dari hasil penelitian pengolahan air minum dengan proses biofiltrasi menggunakan biofilter tercelup dengan media plastik sarang tawon dapat disimpulkan beberapa hal sebagai berikut :

- Pertumbuhan mikroorganisme dilakukan secara alami yaitu dengan cara mengalirkan air baku sungai yang akan diolah ke dalam reaktor secara terus-menerus melalui media PVC sarang tawon hingga terbentuk lapisan biomassa (biofilm) yang melakat pada permukaan media, dan proses berjalan stabil setelah operasi berjalan sekitar 3 minggu.
- Semakin kecil waktu tinggal hidrolis (WTH), efisiesi penghilangan zat organik semakin kecil. Dengan kondisi waktu tinggal hidrolis 1 jam efisiensi penghilangan zat organik 30,92 $\%$ untuk waktu tinggal 2 jam efisiensi sebesar $45,70 \%$ sedangkan pada waktu tinggal 3 jam sebesar $53,89 \%$ dan pada waktu tinggal 4 jam sebesar $64,27 \%$.

- Dengan kondisi waktu tinggal hidrolis 1 jam efisiensi penghilangan zat organik 30,92\% untuk waktu tinggal 2 jam efisiensi sebesar $45,70 \%$ sedangkan pada waktu tinggal 3 jam sebesar $53,89 \%$ dan pada waktu tinggal 4 jam sebesar $64,27 \%$.

- Dengan beban organik antara 0,2 - 1,5 $\mathrm{kg} / \mathrm{m}^{3}$.hari, hubungan antara beban organik dengan efisiensi penghilangan organik menunjukkan hubungan yang linier dengan persamaan $Y=27,193 X+66,866$ dimana :

$$
\begin{gathered}
Y=\text { Efisiensi penghilangan senayawa } \\
\text { Organik (\%). } \\
X=\text { Beban organik ( } \mathrm{kg} / \mathrm{m}^{3} \text { media.hari). }
\end{gathered}
$$

- Efisiensi penurunan amoniak berdasarkan variasi waktu tinggal hidrolis 1-3 jam berkisar antara $48,74 \%$ - $73.59 \%$. Pada pengolahan dengan pengkondisian waktu tinggal hidrolis 1 jam efisiensi penurunan sebesar $48.74 \%$, untuk waktu tinggal 2 jam menunjukkan efisiensi sebesar $67.98 \%$, untuk waktu tinggal 3 jam efisiensi sebesar 73,59 \%.

- Pengolahan pendahuluan dengan proses biofiltrasi pada kondisi waktu tinggal hidrolik (WTH) $1-4$ jam, konsentrasi zat besi dapat diturunkan dengan efisensi penghilangan berkisar antara $20 \%$ sampai dengan $74 \%$.

- Dengan sistem kombinasi biofiltrasi dan ultra filtrasi mempunyai beberapa kelebihan antara lain penggunaan proses biofiltrasi dapat menghilangkan senyawa polutan yang tidak bisa dihilangkan dengan proses konvensional misalnya zat organik, amoniak, deterjen, pestisida, dll. Senyawa tersebut dapat diuraikan dengan proses biologis secara alami (natural).

- Dengan kombinasi proses biofiltrasi dan ultra filtrasi, pengolahan air minum dapat dilakukan tanpa menggunakan bahan koagulan dan flokulan. Dalam hal ini bahan yang digunakan hanya larutan kaporit untuk mendapatkan konsentrasi sisa khlor yang cukup agar tidak terjadi rekontaminasi. 


\section{DAFTAR PUSTAKA}

- "Peraturan Pemerintah Republik Indonesia Nomor : 20 Tahun 1990 Tentang Pengendalian Pencemaran Air ", BAPPEDAL, 1991.

- Water Treatment Hand Book", sixth edition, 1991. Degremont, Lavoisier Publishing, Paris.

- Alaerts, G dan S.S Santika. (1984). "Metoda Penelitian Air". Surabaya. Penerbit Usaha Nasional.

- Barnes, D., Blisse PJ. (1980). "Biological Process Design For Wastewater Treatment'. United States Of America : Prentice-Hall, Inc.

- Benefield, Larry D. (1980). Biological Process Design for Wastewater Treatment. United States of America: Prentice-Hall, Inc.

- Bitton G. (1994), "Wastewater Microbiology". Wiley-Liss, New York.

- Bitton G. (1994), "Wastewater Microbiology". Wiley-Liss, New York.

- Casey, T.J.(1997). "Unit Treatment Process In Water and Wastewater Engineering". University College Dublin, Ireland : John wiley and Sons Ltd.

- Dojlido, jan R, and Best, Gerald A. (1993). "Chemistry of Water and Wastewater Pollution". England. Ellis Horwood Limited.

- Ebie Kunio and Ashidate Noriatsu : "Eisei Kougaku Enshu - Jousuidou To Gesuidou", Morikita Publishing, Tokyo, Japan (1992).

- Fair, Gordon Maskew et.al., " Eements Of Water Supply And Waste Water Disposal', John Willey And Sons Inc., 1971.

- Flatman, Paul E., "Bioremediation : Field Experience, United State of America ", CRC Press, Inc. 1994.

- Gouda T., "Suisitsu Kougaku - Ouyouben", Maruzen kabushiki Kaisha, Tokyo, 1979.

- Grady, C.P.L and Lim, H.C.(1980). "Biological Wastewater Treatment", Marcel Dekker Inc. New York.

- Henry, J. Glynn and Heinke, Gary W. (1996). "Environmental Science \& Engineering". Second Edition. New Jersey, USA. Prentice-Hall, Inc..

- HIKAMI, Sumiko., "Shinseki rosohou ni yoru mizu shouri gijutsu (Water Treatment with Submerged Filter)", Kougyou Yousui No.411, 12,1992.
- Horan, N.J.(1990). "Biological Wastewater Treatment systems : Theory and Operation". University of Leeds, England. John Wiley \& Sons Ltd.

- JICA:" Water Supply Engineering VOL.I ", Edited By Japan Water works Association.

- JICA:" Water Supply Engineering VOL.I ", Edited By Japan Water works Association.

- Lykins,B.W., Moser, R., DeMacro, J. "Treatment Technology in The United States, Disinfection And Controls Of Disinfection By Product", The second Japan - US Governmental Conference On drinking water Quality Management, July 24-26, 1990, Tokyo, japan.

- Metclaf And Eddy , " Waste Water Engineering", Mc Graw Hill 1978.

- Reynold, Tom D., "Unit Operations and Processes in Environmental Engineering", B/C Enginering, United State Of America, 1982.

- Sueishi T., Sumitomo H., Yamada K., and Wada Y., " Eisei Kougaku " (Sanitary Engineering), Kajima Shuppan Kai, Tokyo, 1987.

- Tambo, N and Okasawara, K. " Jousui No Gijutsu (Drinking Water Technology)", GIHOUDOU, Tokyo, Japan (1992).

- Unesco.(1978). "Water Quality Surveys: A Guide for The Collection \& Interpretation of water Quality Data". United Kingdom : IHDWHO Working Group on Quality of Water.

- Viessman W, JR., Hamer M.J., "Water Supply And Polution Control ", Harper \& Row, New York, 1985.

- Winkler, M.A., "Biological Teratment of Wastewater", John Willey and Sons. New York, 1981. 